\title{
Life history traits of Ooencyrtus pityocampae (Hymenoptera: Encyrtidae) reared on Halyomorpha halys eggs (Hemiptera: Pentatomidae)
}

\author{
Hilal Tunca ${ }^{1}$, Marine Venard², Etty-Ambre Colombel$^{2}$, Mathilde Capelli ${ }^{2}$ and \\ Elisabeth Tabone ${ }^{2}$
}

\author{
${ }_{1}$ Ankara University, Faculty of Agriculture, Department of Plant Protection, 06110, Ankara, Dıskapı, Turkey \\ 2 INRA, UEFM site Villa Thuret, Laboratoire BioContrôle, 90 Chemin Raymond, 06160, Antibes, France \\ * Corresponding author: htunca@ankara.edu.tr
}

With 1 figure and 7 tables

\begin{abstract}
The brown marmorated stink bug, Halyomorpha halys Stål (Hemiptera: Pentatomidae) originates from Asia and has recently disseminated to America and Europe, where it is considered as an invasive pest of various crops. Developing biological control strategies is necessary, and egg parasitoids are among the best candidates. In this context, the objective of this study was to evaluate the fitness of the egg parasitoid Ooencyrtus pityocampae Mercet (Hymenoptera: Encyrtidae) reared on $H$. halys eggs, under laboratory conditions. We specifically investigated the impact of host age, host density and length of exposure on $O$. pityocampae life history traits. Host age $\times$ host density and host age $\times$ length of exposure affected the performance of $O$. pityocampae. The optimal emergence rate of the parasitoid was obtained from one-day-old $H$. halys eggs and 3 days of exposure. The parasitoid embryonic development ranged from 17.1 to 18.3 days. The mean longevity of O. pityocampae was 44.1 days. This species reproduces by thelytokous parthenogenesis and the female parasitoid produced an average of 42.6 progeny during their lifespan. Pre-oviposition, oviposition and post-oviposition periods were 1.9 days, 18.8 days and 24.8 days, respectively. These results suggest that $H$. halys is a suitable host for $O$. pityocampae, and may help for the development of a pest-management strategy against $H$. halys.
\end{abstract}

Keywords: Egg parasitoid; stink bug; substitute host; biocontrol

\section{Introduction}

Halyomorpha halys Stål (Hemiptera: Pentatomidae), also called brown marmorated stink bug, is native to East Asia and is known as a polyphagous pest of various crops, damaging vegetables, tree fruits and several species of ornamental plants (Leskey et al. 2012, Rice et al. 2014). This invasive insect pest was first detected in North America (Allentown, Pennsylvania) in 2001 (Hoebeke \& Carter 2003), and then in Virginia in 2004 (Day et al. 2011). Since then, it has been recorded in Liechtenstein (Arnold 2009), Germany (Heckmann 2012), France (Callot \& Brua 2013), Italy (Pansa et al. 2013), Canada (Gariepy et al. 2014), Hungary (Vétek et al. 2018), Greece (Milonas \& Partsinevelos 2014), Romania (Macavei et al. 2015) and more recently in Chile (Faúndez \& Rider 2017). Its rapid spread makes it become a key pest that damage economically relevant agricultural crops (Kriticos et al. 2017, Bosco et al. 2018).
Several studies have demonstrated the effectiveness of various insecticides on the control of $H$. halys (Nielsen et al. 2008, Leskey et al. 2012, 2014; Bergmann \& Raupp 2014, Cira et al. 2017). However, insecticides are dangerous to the environment and human health (Weisenburger 1993, Croft 1990, Desneux et al. 2007), and many insecticides have, over time, gradually lost their effectiveness and their field performance due to the development of pests' resistance (e.g. see Liu et al. 2017). Thus, alternatives have to be developed, among which biological control programs are often considered important part of sustainable pest management strategies.

Egg parasitoids are common biological control agents and are the largest group of entomophagous insects associated with Heteroptera. They attack and kill the host before its development and the first damage on plants (Bin 1994). $H$. halys eggs were observed to be parasitized by three principal groups of hymenopteran egg parasitoids, namely 